\title{
Manufacturing, Packaging or Shipping Problem
}

National Cancer Institute

\section{Source}

National Cancer Institute. Manufacturing, Packaging or Shipping Problem. NCI

Thesaurus. Code C63041.

Problem associated with any deviations from the documented specifications of the device that relate to nonconformity during manufacture to the design of an item or to specified manufacturing, packaging or shipping processes (out of box problem). 